\title{
Analisa Kekuatan Tarik Baja Konstruksi Bj 44 Pada Proses Pengelasan SMAW dengan Variasi Arus Pengelasan
}

\author{
Imam Basori \\ Universitas Negeri Jakarta, Fakultas Teknik, Jurusan Teknik Mesin \\ Jl. Rawamangun Muka, Jakarta Timur \\ E-mail: unimam_r_one@yahoo.com
}

\begin{abstract}
Abstrak
Penelitian ini bertujuan untuk mengetahui pengaruh kuat arus terhadap kekuatan tarik baja kontruksi Bj. 44 pada proses pengelasan SMAW menggunakan kampuh Single $V$ dengan elektroda E6013 pada polaritas DC+ dengan arus 100 ampere, 110 ampere, 120 ampere dan 130 Ampere.

Pengujian tarik dilakukan terhadap spesimen baja konstruksi $\mathrm{Bj} 44$ hasil proses pengelasan SMAW. Sampel yang digunakan dalam penelitian ini menggunakan variasi kuat arus 100 ampere, 110 ampere, 120 ampere dan 130 ampere dengan polaritas terbalik (DC+). Proses pembuatan sampel uji tarik menggunakan standar JIS Z 2201 dan JIS Z 2241.

Hasil pengujian tarik menunjukkan bahwa angka kekuatan tarik tertinggi terdapat pada hasil pengelasan SMAW dengan arus 130 ampere sebesar $547 \mathrm{~N} / \mathrm{mm}^{2}$, dimana 2 dari 3 patahan specimen terjadi pada daerah logam induk, sedangkan kekuatan tarik terendah pada arus 100 Ampere sebesar 497,67 N/mm², dimana 2 dari 3 patahan specimen terjadi pada logam las.
\end{abstract}

Keywords: Kekuatan tarik, Pengelasan SMAW, Kampuh Single V, Elektroda E6013

\section{Pendahuluan}

Salah satu variable yang sangat mempengaruhi kekuatan hasil lasan adalah besar kecilnya arus listrik. Arus akan mempengaruhi besarnya masukan panas pada logam las dan juga berpengaruh terhadap laju pendinginan. Hal ini akan berpengaruh terhadap pola struktur mikro yang terbentuk pada logam las. Fenomena ini akan berpengaruh terhadap kemampuan logam las untuk menahan beban mekanik, salah satunya adalah ketahanan terhadap beban tarik. Besarnya kekuatan tarik logam las dapat diketahui melalui pengujian tarik

Tujuan utama proses pengujian tarik adalah untuk mengetahui kekuatan material menerima beban tarik. Dari hasil pengujian tarik ini akan didapatkan beberapa data seperti kekuatan elastik bahan, kekuatan plastis bahan, kekuatan luluh dan juga kekuatan maksimum bahan menerima beban tarikan. Hasil dari pengujian tarik ini sangat bermanfaat sebagai data acuan untuk diaplikasikan dalam dunia industri. Dari pengujian tarik ini kita juga mengetahui apakah bahan tersebut ulet atau getas.

Pengujian tarik spesimen las dimaksudkan untuk mengetahui berapakah arus yang paling efektif untuk menghasilkan kekuatan tarik maksimum dan pada daerah manakah patahan akan terjadi, daerah las, daerah pengaruh panas atau pada logam induk. Serta untuk mengetahui jenis patah yang terjadi, patahan ulet atau patahan getas. Pembebanan tarik adalah pembebanan yang diberikan pada benda dengan memberikan gaya tarik berlawanan arah pada salah satu ujung benda.

Akibat yang ditimbulkan oleh gaya penarikan terhadap bahan adalah terjadinya perubahan bentuk (deformasi) bahan tersebut. Proses terjadinya deformasi pada bahan uji ini adalah proses pergeseran butiran-butiran kristal logam yang mengakibatkan melemahnya gaya elektromagnetik setiap atom logam hingga terlepasnya ikatan tersebut oleh penarikan gaya maksimum. Penyusunan butiran 
kristal logam yang diakibatkan oleh adanya penambahan volume ruang gerak dari setiap butiran dan ikatan atom yang masih memiliki gaya elektromagnetik, secara otomatis bisa memperpanjang bahan tersebut.

Dengan demikian, sangat beralasan jika dalam pengujian bahan-bahan teknik, kekuatan suatu bahan sering ditentukan oleh kekuatan tarik, misalnya pada tipe baja konstruksi Bj-37, Bj-44 dan Bj-60.

Dalam pengujian tarik ini, batang uji tersebut dibebani dengan kenaikan beban sedikit demi sedikit sampai batang uji patah. Kemudian sifat-sifat tarikannya dapat dihitung dengan persamaan sebagai berikut :

$$
\sigma=\frac{F}{A o}
$$

Dimana : $\sigma=$ Tegangan Tarik $\left(\mathrm{kg} / \mathrm{mm}^{2}\right)$

$\mathrm{F}=$ Beban $(\mathrm{kg})$

$\mathrm{A}_{\mathrm{o}}=$ Luas mula dari penampang batang uji $\left(\mathrm{mm}^{2}\right)$

Karakterisasi material juga bisa kita ketahui dari grafik yang dihsilkan. Dari grafik ini kita bisa mengetahui besarnya tegangan elastic bahan, tegangan plastis bahan, tegangan luluh dan juga tegangan maksimum.

Pada penelitian ini akan dilakukan pengujian tarik terhadap spesimen hasil proses pengelasan SMAW baja konstruksi Bj 44 dengan elektroda E6013 dengan variasi arus pengelasan $100 \mathrm{~A}, 110 \mathrm{~A}, 120 \mathrm{~A}$ dan 130 A dengan polaritas pengelasan terbalik DC+.

\section{Metode penelitian}

Jenis kampuh atau sambung las yang digunakan adalah kampuh single $\mathrm{V}$, dengan root pass $2-3 \mathrm{~mm}$, sudut pembevelan $60^{\circ} \mathrm{s} / \mathrm{d}$ $70^{\circ}$, gap root $3 \mathrm{~mm}$, ketebalan pelat $10 \mathrm{~mm}$. penyiapan bahan dengan menggunakan cutting torch automatic sehingga persiapan spesimen bisa cepat dan tepat dalam waktu maupun dimensi.

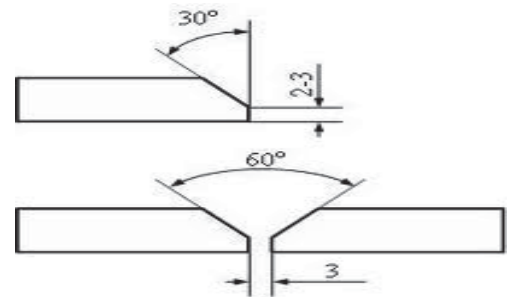

Gambar 1. Kampuh las V

Proses pengelasan dilakukan dengan melakukan variasi arus 100 A, 110 A, 120 A dan 130 A dengan jenis mesin las SMAW DC sesuai dengan pemasangan DC+. Jenis elektroda yang digunakan adalah E6013 dengan diameter elektroda 3,2 $\mathrm{mm}$. Pengujian spesimen yang dilakukan adalah uji tarik.

Baja hasil lasan yang memiliki panjang awal $40 \mathrm{~cm}$ x $20 \mathrm{~cm} \times 1 \mathrm{~cm}$ dipotong vertikal menjadi 2 dengan ukuran masingmasing $20 \mathrm{~cm} \mathrm{x} 20 \mathrm{~cm} \mathrm{x} 1 \mathrm{~cm}$. Proses pembuatan sampel uji tarik menggunakan standar JIS Z 2201 dan JIS Z 2241.

Baja hasil lasan dengan ukuran $40 \mathrm{~cm} \mathrm{x}$ $20 \mathrm{~cm} \times 1 \mathrm{~cm}$ dipotong menjadi 2 bagian, sehingga ukurannya menjadi $20 \mathrm{~cm}$ x $20 \mathrm{~cm}$ x $1 \mathrm{~cm}$ dengan menggunakan mesin gergaji potong. Setelah itu baru dibuat ukuran yang sesuai dengan standar JIS Z 2201 dengan panjang $3 \mathrm{~cm} \mathrm{x} 20 \mathrm{~cm}$ x $1 \mathrm{~cm}$ mejadi 3 spesimen untuk 1 sampel.

Pengambilan spesimen dilakukan dengan daerah lasan berada pada posisi tengah spesimen yang akan dibuat. Hal itu dilakukan untuk mencari kekuatan tarik dari hasil lasan tersebut.

Setelah dipotong mejadi 3 spesimen dengan ukuran masing-masing spesimen 3 $\mathrm{cm}$ x $20 \mathrm{~cm}$ x $1 \mathrm{~cm}$, kemudian untuk membentuk spesimen uji tarik nya menggunakan mesin Frais.

Penggunaan mesin Frais dilakukan untuk mendapatkan bentuk spesimen yang sesuai standar JIS Z 2201 dan JIS Z 2241. Menggunakan Drill dengan diameter 8 mm dengan pemakanan $1 \mathrm{~mm}$. Hal itu dilakukan untuk mengurangi proses perlakuan panas pada spesimen yang akan diuji. 


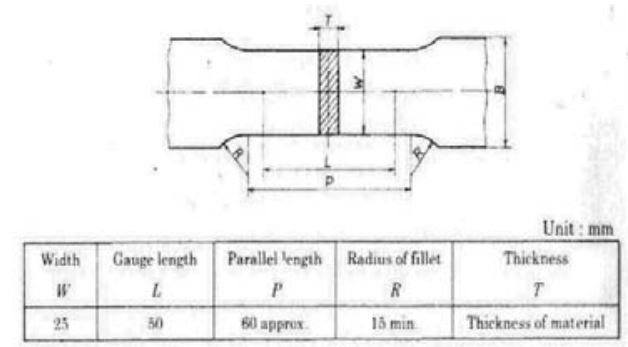

Gambar 2. Ukuran Spesimen Uji Tarik Menurut Standar JIS Z 2201

Adapun penampang specimen sebelum dilakukan pengujian tarik seperti pada gambar dibawah.

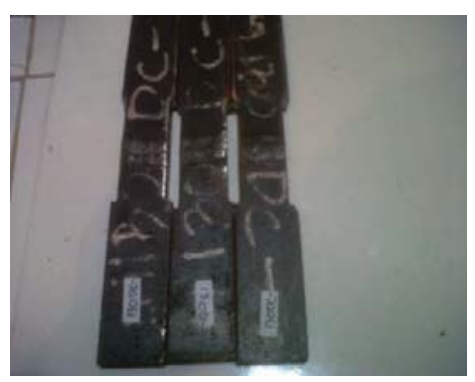

Gambar 3. Spesimen Uji Tarik Sebelum Di $\mathrm{Uji}$

\section{Hasil dan pembahasan}

Pengujian tarik pada polaritas terbalik (DC+) terdiri dari 4 variasi arus yaitu 100 ampere, 110 ampere, 120 ampere dan 130 Ampere dengan masing-masing variasi arus terdiri dari 3 spesimen.

a. Arus 100 ampere Polaritas Terbalik $(\mathrm{DC}+)$

Pengujian tarik pada arus 100 ampere DC+ pada spesimen 1, 2, dan 3 memiliki kekuatan tarik sebesar $487 \mathrm{~N} / \mathrm{mm}^{2}, 521$ $\mathrm{N} / \mathrm{mm}^{2}$, dan $485 \mathrm{~N} / \mathrm{mm}^{2}$.

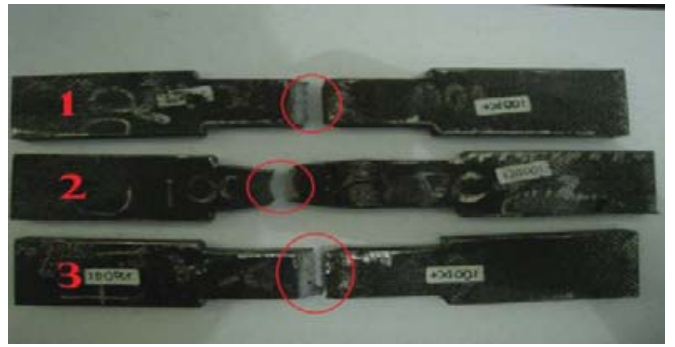

Gambar 4. Spesimen Hasil Uji Impak Arus 100 Ampere DC+

Gambar 4 menunjukkan bahwa hasil pengujian tarik pada arus 100 ampere DC+ pada spesimen 1 dan 3 putus pada daerah lasan sedangkan pada spesimen 2 putus pada daerah logam induk. Sehingga dapat didefinisikan bahwa terdapat kecenderungan kekuatan tarik logam induk lebih baik dibandingkan dengan daerah hasil lasan.

\section{b. Arus 110 Ampere Polaritas Terbalik (DC+)}

Pengujian tarik pada arus 110 ampere DC+ pada spesimen 1 , 2, dan 3 memiliki kekuatan tarik sebesar $538 \mathrm{~N} / \mathrm{mm}^{2}, 543$ $\mathrm{N} / \mathrm{mm}^{2}$, dan $548 \mathrm{~N} / \mathrm{mm}^{2}$.

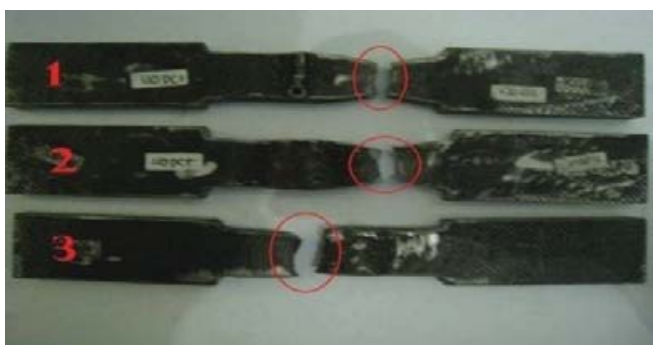

Gambar 5. Spesimen Hasil Uji Impak Arus 110 Ampere DC+

Gambar 5 diatas dapat dilihat bahwa hasil pengujian tarik pada arus 110 ampere DC+ pada spesimen 1 , 2, dan 3 putus pada logam induk. Sehingga dapat didefinisikan bahwa terdapat kecenderungan kekuatan hasil lasan lebih baik dibandingkan dengan kekuatan logam induk

\section{c. Arus 120 Ampere Polaritas Terbalik $(\mathrm{DC}+)$}

Pengujian tarik pada arus 120 ampere DC+ pada spesimen 1, 2, dan 3 memiliki 
kekuatan tarik sebesar $530 \mathrm{~N} / \mathrm{mm}^{2}, 535$ $\mathrm{N} / \mathrm{mm}^{2}$, dan $529 \mathrm{~N} / \mathrm{mm}^{2}$.

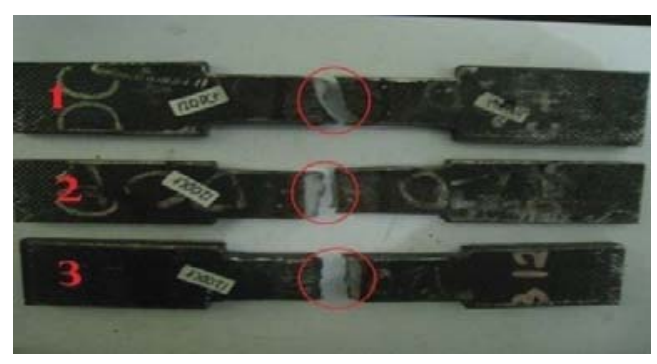

Gambar 6. Spesimen Hasil Uji Impak Arus 120 Ampere DC+

Gambar 6 diatas dapat dilihat hasil pengujian tarik pada arus 120 Ampere DC+ pada spesimen 1 , 2, dan 3 putus pada daerah lasan. Sehingga dapat didefinisikan bahwa kekuatan daerah logam induk lebih baik dibandingkan dengan kekuatan daerah hasil lasan.

d. Arus 130 Ampere Polaritas Terbalik (DC+)

Pengujian tarik arus 130 ampere polaritas terbalik pada spesimen 1 , 2, dan 3 memiliki kekuatan tarik sebesar $545 \mathrm{~N} / \mathrm{mm}^{2}, 550$ $\mathrm{N} / \mathrm{mm}^{2}$, dan $546 \mathrm{~N} / \mathrm{mm}^{2}$.

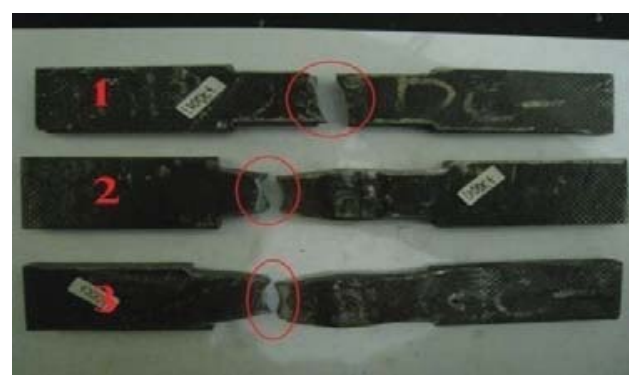

Gambar 7 Spesimen Hasil Uji Tarik Arus 130 Ampere DC+

Gambar 7 diatas dapat dilihat bahwa hasil pengujian tarik arus 130 ampere DC+ pada spesimen 1 putus pada daerah hasil lasan, sedangkan pada spesimen 2 dan 3 putus pada daerah logam induk. Sehingga dapat didefinisikan bahwa terdapat kecenderungan daerah hasil lasan memiliki kekuatan tarik lebih tinggi dibandingkan dengan derah logam induk.
Adapun ringkasan hasil pengujian tarik ditampilkan pada tabel dibawah.

Tabel 1. Hasil Uji Impak Polaritas DC+

\begin{tabular}{|c|c|c|c|c|}
\hline \multirow{2}{*}{$\begin{array}{c}\text { Arus } \\
\text { Pengelasan }\end{array}$} & \multicolumn{3}{|c|}{ Spesimen } & $\begin{array}{c}\text { Rata- } \\
\text { rata } \\
(\text { Ampere) }\end{array}$ \\
\cline { 2 - 5 } & 1 & 2 & 3 & \\
\hline 100 & $\left.487 \mathrm{~mm}^{2}\right)$ & 521 & 485 & 497.67 \\
\hline 110 & 538 & 543 & 548 & 543.00 \\
\hline 120 & 530 & 535 & 529 & 531.33 \\
\hline 130 & 545 & 550 & 546 & 547.00 \\
\hline
\end{tabular}

Berdasarkan data-data yang telah diperoleh, dari hasil pengujian tarik terhadap spesimen dengan proses pengelasan SMAW menggunakan polaritas DC+ dengan variasi arus 100 ampere, 110 ampere, 120 ampere, dan 130 ampere didapatkan grafik seperti gambar 8 .

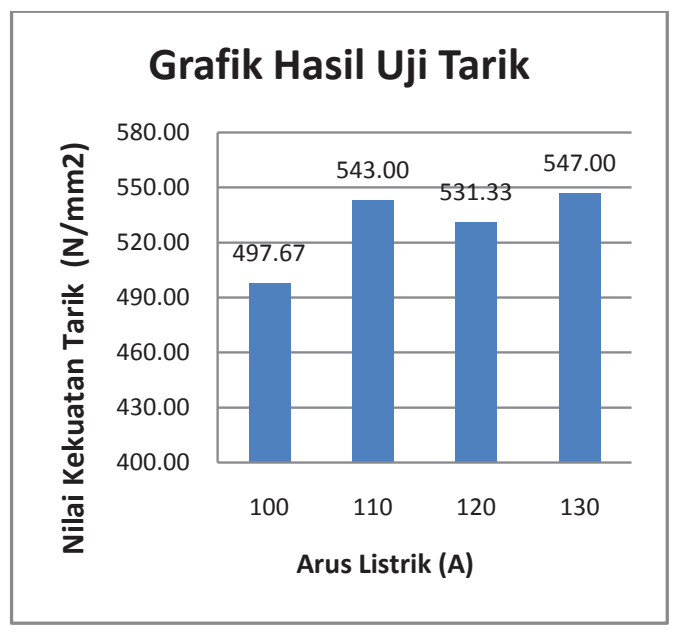

Gambar 8. Grafik hasil uji tarik

Diagram diatas menunjukkan bahwa nilai kekuatan tarik pada proses pengelasan SMAW dengan polaritas DC+ tertinggi terdapat pada arus 130 ampere dengan kekuatan tarik sebesar $547 \mathrm{~N} / \mathrm{mm}^{2}$, dimana terdapat kecenderungan patahan terjadi pada logam induk, hal ini menunjukkan bahwa daerah las memiliki kekuatan tarik lebih 
tinggi lagi. Sedangkan nilai kekuatan tarik terendah pada arus pengelasan 100 ampere sebesar 497.67 ampere, dimana 2 dari 3 patahan specimen terjadi pada daerah lasan.

\section{Kesimpulan}

Dari proses pengujian tarik yang telah dilakukan pada spesimen baja kontruksi Bj. 44 yang telah dilakukan proses pengelasan SMAW menggunakan dan DC+ dengan variasi arus 100 ampere, 110 ampere, 120 ampere dan 130 didapatkan karakterisasi kekuatan tarik sebagai berikut :

1. Kekuatan tarik tertinggi terdapat pada spesimen dengan arus pengelasan 130 Ampere dengan nilai sebesar 547 $\mathrm{N} / \mathrm{mm}^{2}$, dimana terdapat 2 dari 3 spesimen mengalami patahan pada logam induk.

2. Kekuatan tarik terendah terdapat pada spesimen dengan arus pengelasan 100 Ampere dengan nilai sebesar 497,67 $\mathrm{N} / \mathrm{mm}^{2}$ dimana terdapat 2 dari 3 spesimen mengalami patahan pada logam las.

\section{Daftar pustaka}

1. Amstead, B. H. dkk, 1997. Teknologi Mekanik, Jakarta: Erlangga.

2. American welding society, 1993. Specification for Underwater Welding, Miami: AWS

3. Ariestadi, Dian, 2008. Teknik Struktur Bangunan, Jakarta: Direktorat Pembinaan Sekolah Kejuruan.

4. Daryanto, 2010. Proses Pengolahan Besi dan Baja (Ilmu Metalurgi), Bandung: sarana Tutorial Nurani Sejahtera.

5. Sonawan, Hery dan Suratman, Rochim. 2006. Pengantar Untuk
Memahami Proses Pengelasan Logam, Bandung: Alfabeta.

6. Sunaryo, Hery. 2008. Teknik Pengelasan Kapal jilid 1,Jakarta: Direktorat Pembinaan Sekolah Kejuruan.

7. Sungkono, Kh. 1995. Buku Teknik Sipil. Bandung: Nova

8. Surdia, Tata dan Saito, Shinroku. 2006. Pengetahuan Bahan Teknik, Jakarta: Pradnya Paramita.

9. Widharto, Sri. 2009 Inspeksi Teknik Buku 1, Jakarta: Pradnya Paramita.

10. Sindo Kou,1987, Welding Metallurgy, Singapura, A WileyInterscience Publication.

11. Wiryosumarto, Harsono dan Okumura, Toshie. 1996. Teknologi Pengelasan Logam, Jakarta: Pradnya Paramita. 